\title{
EL PAPEL DE LA DIETA MEDIÁTICA EN LA EXPERIENCIA MIGRATORIA DE LA COMUNIDAD HISPANOAMERICANA. REPENSANDO LA RECEPCIÓN A TRAVÉS DE LAS FAMILIAS, LAS REDES Y LOS MEDIOS
}

\section{THE ROLE OF MEDIA DIET IN THE MIGRATION EXPERIENCE OF THE HISPANIC AMERICAN COMMUNITY. RETHINKING RECEPTION THROUGH FAMILIES, NETWORKS AND THE MEDIA}

\section{Dr Luis Concepción Sepúlveda*, Dr. Alfons Medina Cambrón**,} Dra. Sonia Ballano Macías ${ }^{\star \star *}$

\begin{abstract}
Resumen: La dieta y los hábitos mediáticos de las comunidades inmigrantes han sido estudiados desde una perspectiva alejada de las propias interpretaciones de los protagonistas. En este artículo pondremos la mirada en la experiencia mediática de estos nuevos miembros de la sociedad de acogida desde la percepción que construyen de dichos hábitos. El trabajo de campo incluye 8 grupos de discusión con individuos de 5 nacionalidades hispanoamericanas. Asimismo, se realizaron 18 entrevistas en profundidad a diferentes perfiles representativos de la comunidad hispanoamericana. Los resultados nos permiten mostrar cómo la dieta y los hábitos mediáticos son reconstruidos a través de las interacciones, creando una experiencia y una identidad que dotan a la comunidad diaspórica de un nuevo sentido del proceso migratorio. Se activan mecanismos de solidaridad entre hispanoamericanos; se impulsan espacios de encuentro y comunicación y se establecen canales más sólidos para la articulación de la acción cívica, política y cultural dentro del propio grupo.
\end{abstract}

* Investigador de la Facultad de Comunicación y Relaciones Internacionales Blanquerna-URL, LuisGilbertoCS@blanquerna.url.edu

** Profesor Titular de la Facultad de Comunicación y Relaciones Internacionales Blanquerna-URL, alfonsomc@blanquerna.url.edu

*** Profesora Asociada de la Facultad de Comunicación y Relaciones Internacionales Blanquerna-URL, SoniaBM@blanquerna.url.edu 
Palabras clave: inmigración; diáspora; dieta mediática; recepción; medios étnicos

Abstract: The media diet and habits of immigrant communities have been studied from a perspective far removed from the interpretations of the protagonists themselves. This article will focus on the media experience of these new members of the host society, from the perceptions they construct from these habits. The fieldwork was based on eight focus groups made up of five Hispanic American nationalities. In addition, $18 \mathrm{in}$-depth interviews with different profiles representative of the Hispano-American community were carried out. The results allow us to show how media habits and diet are reconstructed through interactions, creating an experience and an identity which give a new meaning to the migration process for the diasporic community. Solidarity mechanisms are activated; meeting and communication spaces are fostered; and stronger channels for organizing civic, political and cultural action within the group itself are established.

Key words: immigration; diaspora; media diet; reception; ethnic media

\section{INTRODUCCIÓN}

Desde hace décadas, las personas inmigradas de primera y segunda generación buscan construir su identidad en los caminos abiertos por la migración. Algunos se asimilan rápidamente para sentirse integrados y aceptados; otros optan o se ven abocados a la guetificación. Pero en la intersección de estos dos caminos se observan otras respuestas a partir de la (re)construcción de relaciones con las sociedades de acogida, donde juegan un papel muy importante la familia, las redes sociales y los medios de comunicación.

Este artículo tratará de la relación entre inmigración y medios de comunicación, pero alejándonos de los posicionamientos clásicos y focalizando nuestra mirada en la experiencia migratoria y los hábitos mediáticos de los propios migrantes. Así, los discursos de las personas inmigradas nos revelarán cómo se perciben y construyen dichos hábitos (Concepción y Medina, 2011; 2015). También dividiremos su dieta mediática en 3 áreas: la que mira a la sociedad de partida; los modelos híbridos que constituyen los medios étnicos 
y el contacto con otros medios de comunicación, actores y espacios que operan en la sociedad anfitriona.

Las primeras investigaciones en comunicación, que tomaron como objeto de estudio la inmigración, se centraron en la imagen y en los estereotipos de las personas inmigrantes en la prensa (Retis y Benavides, 2005; Bañón, 2008; Concepción et al., 2008; Checa y Arjona, 2011; Giró, 2006; Giró y Jarque, 2006; Igartua y Muñiz, 2007). Por tanto, el análisis de este fenómeno poliédrico, con múltiples relaciones entre comunicación e inmigración, se circunscribía, preferentemente, al papel de los medios de comunicación en la representación de los nuevos ciudadanos. Estas investigaciones aportaban una reflexión pausada a la escalada informativa de signo negativo.

De manera paulatina, se inició una apertura hacia la inmigración como una nueva audiencia desde la recepción mediática (Sampedro, 2003; Bernárdez, 2007; Gualda y Montes, 2007; Navarro, 2015). Este cambio se intensifica con el inicio de la crisis económica, pero no significará que se deje atrás la preocupación inicial por el análisis de la representación mediática, que sigue muy presente en la actualidad. Así comienzan a surgir diferentes posicionamientos teóricos, que abonarán el camino hacia un nuevo interés centrado en el uso que hacen las propias personas inmigradas de los medios y qué opinan de estas imágenes dominantes en el sistema mediático.

Durante la agudización de la crisis económica, algunos investigadores también empiezan a fijarse en los nuevos medios (latinos, sobre todo) y surgen los primeros trabajos exploratorios, la mayoría de los cuales se dedican a inventariarlos, describirlos y clasificarlos. Estos medios todavía se encontraban en su mejor momento, tanto en variedad de la oferta como en su circulación en las ciudades, sobre todo los gratuitos, que se repartían en metros, locutorios y en el comercio floreciente inmigrante (GómezEscalonilla, 2008; Sabés-Turmo, 2009a y 2009b; Gómez-Escalonilla y Santín, 2012; Altarriba et al., 2008).

En España, se ha producido una emergencia de dichos medios, también llamados medios étnicos o de la diáspora. Este concepto vuelve a cobrar actualidad en los últimos años, aplicado a las situaciones de inmigración, para referirse a las poblaciones diseminadas por el mundo en el contexto de migraciones internacionales. Son colectivos que mantienen contacto con las sociedades de origen tanto como con otras comunidades nacionales 
que residen en otros países. En la diáspora el individuo conecta con el término transnacionalidad como forma de vida (Concepción y Medina, 2011).

Los medios latinos juegan un papel relativamente importante en el proceso migratorio (Gómez-Escalonilla y Santín, 2008) porque cubren necesidades informativas no satisfechas. Su consumo ayuda a reafirmar las identidades colectivas de las personas inmigradas en su acomodación a las sociedades de acogida y marchan en paralelo a nuevas comunidades que se fundamentan en redes sociales transfronterizas.

Sin embargo, el interés de este nuevo fenómeno comunicativo no estriba únicamente en su papel corrector de la invisibilidad mediática y en su capacidad de ofrecer alternativas al acercamiento infructuoso de la audiencia étnica a los medios españoles. La puesta en escena de los medios étnicos concede un mayor dinamismo al concepto de mundo de la vida de las personas inmigradas porque, además de contribuir a la tradición y a la renovación del saber cultural, establece canales más sólidos para una mayor coordinación de la acción de dichas comunidades (Habermas, 1999). Los medios étnicos cumplen esta función al intensificar la integración social y la creación de mecanismos de solidaridad entre las personas inmigrantes.

\section{ESTUDIOS SOBRE LA RECEPCIÓN MEDIÁTICA DE LOS PROCESOS DE INMIGRACIÓN}

Los estudios sobre la recepción mediática de los procesos de inmigración han generado pocas aproximaciones al consumo mediático que no sean deudoras del esquema de pensamiento de los países occidentales. Suelen partir de una relación asimétrica de fuerzas entre la sociedad anfitriona, mayoritaria y sedentaria, y dichas comunidades, minoritarias y en permanente movimiento. Desde una perspectiva histórica, el nacimiento del estado nación institucionaliza en las sociedades autóctonas (Altarriba et al., 2008) una forma muy arraigada de definirse que bebe de los elementos esencialistas de la identidad nacional, del sentimiento de pertenencia al territorio y del abrigo de una colectividad unida que comparte una misma cultura. 
Este concepto de identidad colectiva entra en el juego de dicotomías o sistemas binarios con los que la sociedad de acogida se comprende a sí misma y a la alteridad. Sus fundamentos son el trasfondo de numerosos trabajos sobre los efectos de la recepción, anclados en sistemas binarios que se complementan: integraciónmarginación (Altarriba et al., 2008; Sendín, 2014); sedentarismotransnacionalismo (Georgiou, 2014); asimilacionismo-guetización (Ortiz y Behm-Morawitz, 2015); lealtad-deslealtad a la sociedad anfitriona (Bauböck, 2004). Estas parejas de conceptos guardan una relación simbiótica que se retroalimenta de su contraposición. Esto produce un claro refuerzo identitario que visualiza permanentemente las identidades como elementos diferenciadores.

En la bibliografía internacional sobre la recepción mediática de las minorías étnicas y culturales, dominan tres formas de entender la recepción mediática que se derivan, directa o indirectamente, de estos sistemas binarios: a) la recepción desde la integración de las personas inmigradas; b) el estudio del impacto directo del mensaje mediático; y c) la recepción desde el paradigma transnacional.

a) La recepción mediática desde la integración de las personas inmigrantes:

Es una de las corrientes más presentes en EE.UU. desde los años 80. Una parte significativa de la bibliografía sobre la recepción mediática de los hispanos, afroamericanos y otras minorías trabaja con la noción de aculturación; un eufemismo de la expresión asimilación cultural (Moon, 2003; Walker, 1999; Ortiz y Behm-Morawitz, 2015). Si el consumo mediático colabora con la aculturación de las minorías en diferentes grados, las representaciones mediáticas influyen en las actitudes y en la autopercepción de un grupo social y en la imagen que se forme de la alteridad (Mastro, 2015; Hurley, Jensen y Weaver, 2015).

Desde hace años el debate político sobre la integración de las personas inmigrantes en España se ha extendido a toda la sociedad, incluidos los medios y la universidad. De ahí que el estudio de la recepción mediática desde el ángulo de la integración también sea la norma en el corpus de trabajos en España (Martínez y Huertas, 2014; Sendín, 2014; Hernández y Alcoceba, 2015). Esto se debe, en parte, a que los investigadores no acaban de librarse de los intereses y los miedos de una sociedad anfitriona que teme que los nuevos 
ciudadanos amenacen la cohesión social o generen comunidades paralelas.

b) El estudio del impacto directo del mensaje mediático:

La medición del impacto directo de los medios de comunicación sobre la audiencia recoge las respuestas más condicionadas. En estos trabajos, las teorías del encuadre y de la agenda-setting explican una influencia mediática limitada por otros agentes sociales (Igartua, Otero y Muñiz, 2006; Igartua y Frutos, 2016). Estos estudios evalúan la repercusión negativa de determinadas representaciones mediáticas en la percepción social de un grupo minoritario. La recepción de las noticias sobre los «que no son como nosotros» es clave, así, en las actitudes de la sociedad anfitriona y en los procesos de integración o marginación a los que someten a las minorías. En consecuencia, se mantiene una conexión muy clara con la recepción mediática desde la integración de las personas inmigrantes. No preocupa, por tanto, la recepción en sí misma, ni cómo incide en los procesos de socialización que desencadena fuera del eje integraciónmarginación. Estos estudios restringen la recepción al consumo inmediato y parten de los efectos psicológicos del discurso mediático, como los mecanismos mentales de activación de prejuicios.

c) La recepción desde el paradigma transnacional:

Representa un intento por superar la metodología etnocéntrica a través de la incorporación de términos como transnacionalidad y diáspora. El primer concepto remite a la inclusión de las sociedades de partida y de llegada en el estudio de las migraciones internacionales, mientras el segundo, a los espacios diaspóricos que trascienden los lugares adscritos a los estados nación. Sus principales impulsores proceden de Europa y son Georgiou (2014), Tsagarousianou (2017), Rigoni (Rigoni y Larrazet, 2014) y Bailey (2012). Con sus investigaciones, dan un giro a los trabajos sobre recepción mediática de la diáspora en Europa durante la primera década del siglo XXI. El eco de su influencia llegará a España más tarde. Su concepto central, el transnacionalismo, se inscribe también en uno de los sistemas binarios en los que la sociedad anfitriona, voluntaria o involuntariamente, encierra la recepción mediática de las minorías. Así, los estudios, conscientemente o no, parten de una mirada que 
bascula entre términos opuestos de un nuevo sistema binario, lo que resta libertad de interpretación al proceso de recepción. El transnacionalismo que aportan las personas inmigradas se coloca frente al sedentarismo de la sociedad autóctona, en una definición que nace en oposición a su contrario. Más allá de constituir un elemento más de análisis, el transnacionalismo es, prácticamente, el único ángulo desde el que se estudian los grupos sociales minoritarios.

\section{REPENSANDO LA RECEPCIÓN}

El marco teórico de esta investigación reclama un conocimiento más libre de prejuicios y una aproximación a la recepción mediática de las personas inmigradas y las minorías que prescinda de los intereses y temores de la sociedad de acogida (Concepción y Medina, 2011, 2015). Más allá de las dinámicas de acomodación de las personas inmigrantes, de la asimilación o el mantenimiento de su identidad cultural, de la contraposición de formas de vida transnacionales frente al sedentarismo de las audiencias nacionales, queda un largo camino por recorrer en la descripción de una recepción que conecte con procesos de otro orden. Esto significa cambiar la perspectiva desde la que trabaja la recepción mediática.

Es importante dejar atrás la idea preconcebida de que la inmigración y las minorías étnicas y culturales son un fenómeno separado de la sociedad de acogida; si bien es cierto que, como audiencia, posee sus propios patrones de conducta socioculturales (Hall, 1980; Morley, 1996, 1997) y se mueve en ambientes sociales distintos a la sociedad mayoritaria. Desarrolla, asimismo, estrategias de vida transnacionales y mantiene identificaciones múltiples con las culturas y los estados (Bauböck, 2004). Esto dibuja una nueva forma de consumo mediático con causas motivacionales y afectivas diferentes a las del público sedentario de los estados nación.

Con un enfoque distinto, estamos en disposición de abarcar un concepto de recepción mediática más amplio: desde el escenario inmediato del consumo hasta el proceso de socialización que desencadena; conectando la recepción con las diferentes áreas de la vida cotidiana y reflejando su papel en la singularidad del sujeto, en las relaciones sociales, en la cultura y en el sistema. Definiremos el sujeto de estudio como el producto de las tradiciones en las que ha 
vivido, de los grupos solidarios a los que pertenece y de los procesos de socialización en los que ha crecido (Habermas, 2008).

Así, la estructura interna del discurso oral de los miembros de un colectivo tiene características narrativas únicas y guarda un paralelismo extratextual con las dimensiones del mundo de la vida, por cuanto responde al contenido semántico de las tradiciones culturales, al tiempo histórico de la sucesión de generaciones y al espacio social de los grupos socialmente integrados (Habermas, 1999).

Se trata, por tanto, de interpretar los argumentos del sujeto en sus exposiciones orales y el sentido que atribuye a sus apropiaciones mediáticas y tecnológicas; que están influidas por el sesgo de la sociedad de origen y expuestas a un entramado de relaciones afectivas, sentimientos de pertenencia y discursos de identidad colectiva que no conviene olvidar. Se parte de una visión de la comunicación más transversal, que explique las relaciones individuo-sociedadcultura que componen los discursos. También tendremos presente que las migraciones no sólo cuestionan el concepto de experiencia mediática con el que se venía trabajando, sino que además invitan a replantear el papel del medio de comunicación con la aparición de los nuevos medios. La complejidad de la asunción mediática, las motivaciones afectivas, intelectuales, identitarias y comunicativas que llevan a consumir contenidos mediáticos, son objeto de análisis en esta investigación (Habermas, 1999; Concepción y Medina, 2011; Concepción y Medina, 2015; Tortajada, 2009; Tortajada, Comas d’Argemir y Martínez, 2014).

\section{METODOLOGÍA}

Centramos el trabajo de campo en el colectivo hispanoamericano, región extracomunitaria con más peso demográfico en la provincia de Barcelona, según datos del departamento de Estadística del Ayuntamiento de Barcelona ${ }^{1}$. En la actualidad, las nacionalidades más numerosas son: Bolivia, Ecuador, Perú, Colombia, Honduras, Argentina y República Dominicana.

1 Datos de la población extranjera en Barcelona en octubre de 2016. Ajuntament de Barcelona. Departament d'Estadística. Gabinet Tècnic de Programació. La població estrangera a Barcelona. 2016.http://www.bcn.cat/ estadistica/catala/dades/inf/pobest/pobest16/pobest16.pdf 
A partir de una metodología de tipo cualitativo se llevaron a cabo 10 entrevistas exploratorias con expertos en el ámbito de estudio para definir las variables de análisis; 18 entrevistas en profundidad a diferentes perfiles de la comunidad hispanoamericana, para dibujar una cartografía más detallada de las relaciones entre la apropiación mediática y los fenómenos sociales, culturales e individuales. Estas sirvieron para conocer de primera mano las impresiones de los distintos representantes del colectivo, como los presidentes de asociaciones y federaciones latinas; periodistas y directores de medios de la diáspora; responsables de importantes movimientos político-religiosos; y despachos de abogados especializados en extranjería de Barcelona. Asimismo, hemos contrastado estas entrevistas en profundidad con 8 grupos de discusión con 61 personas de 5 nacionalidades (boliviana, ecuatoriana, colombiana, peruana y dominicana). Las 61 personas que formaron parte de los grupos de discusión se situaban entre los 20 y los 49 años. Esta franja de edad representa el 70,64\% de la población hispanoamericana de la provincia de Barcelona según el Idescat. La muestra estuvo formada por un $60 \%$ de mujeres frente a un $40 \%$ de hombres, que se correspondía también con la proporción de latinoamericanos en Barcelona por género.

\section{TABLA 1}

\section{OBJETIVOS DE LOS GRUPOS DE DISCUSIÓN}

\begin{tabular}{|l|}
\hline Recoger el relato de la experiencia mediática. \\
\hline Obtener una panorámica de la dieta mediática de los diferentes colectivos. \\
\hline Comprender cómo se conecta el consumo mediático con la vida cotidiana. \\
\hline Analizar la actitud y percepciones frente al tratamiento mediático. \\
\hline Entender el porqué de las elecciones mediáticas. \\
\hline
\end{tabular}

Fuente: elaboración propia.

A través de cuatro variables definidas con la ayuda de las 10 entrevistas exploratorias, nos acercamos a la experiencia mediática de la diáspora a partir de un orden preestablecido, analizando su dieta mediática en cada uno de los campos en los que tiene lugar. Por un lado, a partir de la variable Medios Generalistas, estudiamos el 
comportamiento de su consumo mediático en el contexto espacial más inmediato, el país de acogida. Con Actualidad del País de Origen, buscamos cómo y por qué se produce una recepción que vuelve su mirada sobre la sociedad de partida y qué medios escogen para informarse y comunicarse. Por la propia naturaleza de su información, la variable Medios Latinos se coloca en un punto intermedio, a caballo entre el país de origen y el de acogida. Finalmente, en Otros Actores, se amplía el foco y se desarrolla una perspectiva distinta a la de la recepción. En ella se pasa revista a todas las entidades que también contribuyen a generar espacios de comunicación, información y socialización en una comunidad étnica en la que los medios latinos han perdido el protagonismo que tuvieron hace muy pocos años.

\section{RESULTADOS}

\subsection{La relación con los medios generalistas}

Las elecciones y apropiaciones mediáticas de los grupos estudiados se mueven en parámetros nacionales de forma prioritaria y, en segundo término, supranacionales, porque aluden a sentimientos de pertenencia más generales como la identidad latina. Estos parámetros nacionales de alcance simbólico, social y cultural, cumplen funciones muy importantes: a) frenan el asimilacionismo y la pérdida de referentes culturales; b) siguen trabajando la cohesión interna del colectivo en situaciones muy adversas; c) contribuyen al mantenimiento de la diversidad cultural; y d) impulsan el consumo transnacional.

En los grupos de discusión surgen expresiones de indefensión contra un discurso que pone en tela de juicio aquello que más quieren después de la familia nuclear, los orígenes. También afloran manifestaciones de rencor que son síntoma de resistencia frente a un relato mediático que asocia lo latino a lo defectuoso. Estas declaraciones concuerdan con los resultados que se desprenden de estudios como el presentado por Red Acoge (2015) donde se evidencia que hasta un $90 \%$ de las personas inmigradas no se sienten representadas en los medios de comunicación.

Otro de los denominadores comunes en los grupos de discusión es la consideración que tanto los medios de comunicación como los españoles hablan de los hispanoamericanos en términos 
culturalistas, partiendo del supuesto que su cultura es superior: «que la cultura es muy baja y que realmente por lo mismo las pandillas son muy conflictivas» (Hombre E5).

Las opiniones de los entrevistados coinciden plenamente con los estudios (Dallemagne, Echevarría y Fernández, 2012) realizados desde finales de los 90 respecto a las políticas de representación de la inmigración en los medios generalistas españoles. Las minorías étnicas y culturales basculan entre la invisibilidad y la visibilidad mediáticas. Es decir, una dicotomía dominada por la ausencia de información sobre minorías, pero a la par, una tendencia a la conflictividad en los medios (robos, terrorismo, drogas, prostitución, violencia...).

La selección de contenidos con los que se sienten identificados es fundamental. Cuando encuentran un espacio dedicado a su cultura, como ocurrió en un episodio del programa de Canal 33 (Televisió de Catalunya) Karakia, es recordado: «Un programa que sí que enfoca una parte de la inmigración positiva es Karakia. ¿Lo conocen? (...) Sólo se enfoca en el tema culinario de su país» (Mujer A1). Estos programas han descrito un recorrido efímero e irregular y han tenido un seguimiento escaso de los colectivos inmigrantes (Altarriba et al., 2008). Así, para el administrador de Fedelatina, Hermes Castro, si tradicionalmente la sociedad catalana ha sido inclusiva con la migración, los medios de comunicación públicos también deberían serlo. Esta idea le da pie a hablar del concepto medio de comunicación inclusivo:

«No me refiero a que le den un espacio exclusivo. Lo que buscamos es participar con la sociedad catalana. No se trata de decir: de las 24 horas de la parrilla les vamos a dar una para que ustedes se 'desparrillen'. Eso no nos interesa, porque si es esa hora todos los catalanes cambiarán de canal y nos mirará solamente el colectivo latinoamericano. Lo que queremos es que en la programación habitual estemos incluidos todos».

Existen otras razones que explican las elecciones mediáticas de los hispanoamericanos. En un primer momento, la reacción de los latinos es muy emocional y tiene que ver con la rabia, la frustración y la indignación al comprobar que las pocas oportunidades en las que aparecen se producen en clave negativa.

Luz Elena Plasencia, del Centro Peruano de Barcelona, recuerda que, tras los robos en autopistas de una banda de peruanos, desde la 
Consejería de Interior de la Generalitat se declaró que «los peruanos teníamos tendencia a delinquir (...) y estas declaraciones hicieron mucho daño a la colonia peruana» ${ }^{2}$.

La familia que reside en el país de acogida y las reuniones y conversaciones con otros miembros de la diáspora son fundamentales para rearmar de sentido y generar argumentaciones que se resisten a aceptar como válidos los mensajes de los medios generalistas. Las imágenes estereotipadas de lo latino pueden generar miedo y desconfianza en la vida diaria de los hispanoamericanos y tensión en sus relaciones sociales con los catalanes y españoles. Algo similar ocurre entre los miembros de la sociedad mayoritaria. Por otra parte, existe la percepción de que no hay una relación de correspondencia entre los medios generalistas y los principales actores sociales de la comunidad latina en Barcelona (asociaciones, federaciones y otras entidades). Al contrario, esta relación se percibe como unidireccional e interesada porque dicen que los medios los instrumentalizan a su antojo.

La crisis es el telón de fondo de la vida cotidiana e influye en la relación con los medios. Algunos miembros de los grupos de discusión se refieren a la crisis económica para explicar un cambio de actitud hacia lo latino, tanto en los medios de comunicación como en los círculos sociales. Por ejemplo, se habla de:

«(...) hipocresía en la televisión y en la radio, porque en el pasado, en el boom migratorio, los inmigrantes eran buenos para este país. Había gente que no quería hacer ciertos trabajos y le daba igual que estos puestos fueran ocupados por inmigrantes. Pero ahora, como hay menos trabajo, nos ven como un estorbo» (Hombre, B4).

Para otros, la crisis también se ha traducido en menos espacios mediáticos dedicados a las migraciones y minorías étnico-culturales, así como en un retroceso en el tratamiento informativo. En este punto, algunos consideran que los medios generalistas no se han hecho eco de los dramáticos desahucios y desalojos que les han afectado, pese a ser el primer colectivo en sentir las consecuencias de la crisis.

2 Público (5-9-2011). «Puig dice que hay nacionalidades con tendencia a delinquir». (Diario Público) 
También es recurrente el rechazo a determinados contenidos televisivos por no ser edificantes. En algunos casos, las profundas convicciones religiosas están en la base de una susceptibilidad que lleva a reducir al máximo el consumo televisivo por considerarse poco constructivo: «Lo que pasa en la televisión realmente no edifica mi vida; incluso a los niños, hay cosas que pasan ahí que no pueden ayudar a educar...» (Hombre E3).

Por otra parte, las minorías hispanas reparten su elevado consumo entre los medios de su país de origen, los latinos y los generalistas de Barcelona y España (Soriano, 2009, p.1). Si añadimos su actitud crítica frente a los medios autóctonos, la discrepancia o el rechazo a una parte importante de sus contenidos, es normal que este consumo sea algo inferior al de los españoles. Precisamente, uno de los aspectos más demandados es una mayor sensibilidad informativa que recoja los cambios que se están produciendo en Hispanoamérica en términos sociales, económicos y educativos.

\section{TABLA 2}

\section{TIPOLOGÍA MOTIVACIONAL DE LAS ELECCIONES MEDIÁTICAS (MEDIOS GENERALISTAS)}

\begin{tabular}{|l|l|}
\hline Parámetros nacionales & $\begin{array}{l}\text { Explican la búsqueda de información que hable de su país de origen } \\
\text { y la identificación con sus contenidos. }\end{array}$ \\
\hline $\begin{array}{l}\text { Actitud defensiva frente a las } \\
\text { imágenes estereotipadas }\end{array}$ & $\begin{array}{l}\text { A menudo no se sienten representados ni interpelados por los } \\
\text { productos mediáticos. }\end{array}$ \\
\hline Crisis económica & $\begin{array}{l}\text { La crisis económica ha modificado sus elecciones mediáticas. Se } \\
\text { evitan informaciones sobre la crisis y se prima el entretenimiento, la } \\
\text { prensa deportiva y los programas de actualidad en clave humorística. }\end{array}$ \\
\hline Educación cristiana & $\begin{array}{l}\text { La presencia del cristianismo en la vida de los latinos refuerza una } \\
\text { educación moral que no se siente cómoda en numerosos espacios de } \\
\text { la televisión generalista. Buscan contenidos edificantes en valores. }\end{array}$ \\
\hline
\end{tabular}

Fuente: elaboración propia.

\subsection{La actualidad del país de origen: apropiación y uso de los medios y las tic}

La conformación de hogares con familias separadas por la distancia, la configuración social de las comunidades latinas y el 
rol de las cadenas migratorias ${ }^{3}$ explican, en parte, la experiencia mediática de los hispanoamericanos. Si bien cada comunidad tiene sus peculiaridades, las minorías hispanas comparten una serie de pautas de apropiación que tienen que ver con elementos socioculturales afines. La familia está en primer plano en el proceso migratorio y en la experiencia mediática: es depositaria de la confianza en la interpretación de la actualidad informativa de Hispanoamérica, en el cuidado de los hijos que se han quedado en origen y también del capital emocional de las comunicaciones.

Las TIC permiten mantener el canal permanentemente abierto con la familia en origen, para afianzar los vínculos y atribuir una importancia vital al flujo de comunicación e información que procede de los parientes lejanos. Un flujo de información que también es clave en las decisiones más transcendentales de la diáspora, tanto en el inicio del proyecto migratorio como en el retorno al país de origen. La interpretación de las noticias que vienen del país de origen, así como de aquellas informaciones generadas en Cataluña sobre el país de nacimiento - a menudo invisibilizadas por los medios generalistas-, son funciones de primer orden en la comunicación con la familia. En esta línea, la mayoría de los que formaron parte de los grupos de discusión no dudaban cuando se les preguntaba acerca de cómo se enteraban de algo que había pasado en su país.

A su vez, y pese a todos los avances de las TIC, el canal prioritario para comunicarse con la familia sigue siendo la llamada internacional. El abaratamiento del precio, la sensación de cercanía y la dimensión humana que adquiere la comunicación son aspectos fundamentales en interacciones sociales que tienen un gran componente afectivo. A través de las llamadas internacionales, la familia se convierte en el eje central y es el punto de partida desde el que se ponen en marcha procesos sociales, culturales e identitarios:

«Yo me informo y contrasto la información, porque tengo la llamada gratis a fijo. Me interesa mucho la opinión de mi hermana porque está muy informada y tiene un criterio acorde con mi forma de pensar (...) Leo, me formo una idea y luego siempre le pido opinión» (Mujer G1).

3 Siempre hay un familiar que ha llegado antes a Barcelona y que ayuda al resto a establecerse en suelo catalán. 
La investigadora Jessica Retis concede al teléfono un lugar preeminente entre los medios de comunicación más empleados por los latinos.

El 95\% de los latinoamericanos en España mantiene contacto constante con su país. El medio de comunicación más utilizado es el teléfono (97\%): el 66\% llama por lo menos una vez por semana (especialmente los colombianos y bolivianos) y el 30\% lo hace quincenal o semanalmente. Los servicios de Internet, en este punto, ocupan un segundo lugar en la comunicación con los familiares que residen en el país de origen: un 37\% de los inmigrados utiliza sus correos electrónicos o el chat (Retis, 2013, p. 22):

«Escribir en una red social es una cosa fría. Yo prefiero llamar por teléfono, y llamo a un teléfono fijo (...) el escuchar la voz, el hablar por teléfono, siento a la persona un poco más cerca...» (Mujer G3).

Esto no significa que las redes sociales y plataformas de comunicación digital no jueguen un papel importante en sus relaciones y comunicaciones con la sociedad de origen. Así, Whatsapp es identificado como una herramienta de comunicación directa con familiares y amigos. Le atribuyen un uso más individual y privado, como un servicio útil para comunicarse con personas específicas. A su vez, destacan que es una alternativa más económica a las llamadas internacionales. De ahí que, para las comunicaciones transnacionales, a menudo se empleen las notas de voz y no los mensajes de texto.

Si bien Whatsapp desarrolla un rol relevante en la comunicación con la sociedad de origen, también lo hace en la sociedad de destino y en contextos muy diversos. Los miembros de los grupos de discusión dicen usar este servicio en su día a día con compatriotas y españoles. Se considera como "un medio más sencillo, más rápido y que se utiliza más» (Mujer C1). A su vez, también se destaca, en múltiples ocasiones, que "facilita la comunicación con el centro de trabajo» (Mujer B2 y Hombre B3). Mientras que, en el caso de Facebook, la mayoría de los contactos son de la misma nacionalidad, la agenda de contactos de Whatsapp se reparte más entre personas de la misma nacionalidad, catalanes y españoles. La apropiación de esta tecnología entre las comunidades hispanoamericanas se enmarca en la esfera de la comunicación interpersonal, con pocas concesiones 
a los chats de grupo, a excepción de los del trabajo. Whatsapp es, por consiguiente, una herramienta que establece espacios para la interculturalidad virtual; consolidando relaciones de amistad y de trabajo que están teniendo lugar en la vida cotidiana.

A diferencia de Whatsapp, Facebook y otras redes sociales similares, multiplican la red de relaciones con miembros de su comunidad, tanto en la sociedad de origen como en destino. Actúan en dos direcciones. Por un lado, dan rienda suelta a la creación de redes de solidaridad comunitaria en el país de acogida y, por otro lado, ponen en marcha redes de solidaridad transnacional o redes diaspóricas, que permiten al latino involucrarse y participar en movimientos sociales y en eventos que están teniendo lugar en la otra punta del mundo.

Las redes sociales poseen, por tanto, un papel destacado como medios de información, comunicación y relación; substituyendo, en buena parte el consumo de televisión tradicional. Ésta ha dejado de ser el medio principal de acceso a contenidos y vídeo. Su modelo de negocio está siendo desafiado por nuevos canales digitales y un consumo creciente no lineal (Strategy\&, 2015, p. 10). Frente a la representación pobre de la realidad de la diáspora en los medios generalistas, los vídeos en internet suplen esta carencia y explican que la necesidad de obtener más información esté por encima del entretenimiento como fuente de motivación. La muestra estudiada consume vídeos sobre la actualidad informativa que comparten en Facebook sus amigos y familiares del país de procedencia, comunidades creadas en torno al origen común o a un determinado tema. Los vídeos que se consumen como entretenimiento son aquellos que publican en Facebook los contactos de su país de origen, así como los programas de ocio de la televisión hispanoamericana que consumen a través de sus respectivas webs y canales de YouTube. A su vez, cada vez es más habitual la aparición de nuevos formatos de televisión de pago, como los paquetes temáticos que ofrecen algunas cadenas para audiencias latinas. Por otra parte, numerosas cadenas hispanoamericanas también transmiten sus contenidos televisivos por Internet. Y es que la red es el nuevo soporte y espacio aglutinador de todos los medios tradicionales. Entre los latinos que formaron parte de este estudio, los usos de Internet fueron muy variados y algunos peruanos, ecuatorianos y dominicanos veían vídeos de YouTube, así como programas de televisión en vivo o en diferido, de manera regular, a través de páginas web de cadenas de televisión: 
«Yo también leo los periódicos, pero en estos últimos dos años se ve muy poca información de Perú. Si te metes por Internet, lógicamente vas a encontrar más; pero por televisión muy poco. Cuando hay una noticia mala sí sale» (Mujer G2).

La prensa digital de los países de origen también es importante en la vida de la diáspora, pero parece que tiene un lugar más discreto que las redes sociales. Los latinos consultan con cierta regularidad la prensa de sus países, desde estatales como las cabeceras dominicanas Listín Diario, Nuevo Diario, Diario Libre y Hoy y la peruana La República, a regionales como Diario de Chimbote, también de Perú. Facebook y los diarios digitales están, por tanto, muy presentes en la satisfacción de necesidades informativas que están relacionadas con el país de origen.

Los colectivos que no mencionan los diarios digitales de Hispanoamérica son aquellos en los que hay otro canal de comunicación muy utilizado: las llamadas internacionales, los medios latinos y las redes sociales.

\section{TABLA 3}

TIPOLOGÍA MOTIVACIONAL DEL USO DE LAS TIC Y LAS ELECCIONES MEDIÁTICAS. ACTUALIDAD DEL PAÍS DE ORIGEN

\begin{tabular}{|l|l|}
\hline $\begin{array}{l}\text { Contacto con la } \\
\text { familia en origen }\end{array}$ & $\begin{array}{l}\text { Es estratégico por razones emocionales, comunicativas e informativas. } \\
\text { Emocionales: porque la vida en diáspora conlleva una dura experiencia } \\
\text { afectiva que crea la necesidad de mantener el canal abierto con la } \\
\text { familia; comunicativas: porque la familia está detrás de las decisiones } \\
\text { más importantes del proyecto migratorio. Informativas: porque es fuente } \\
\text { de información fiable y prioritaria, clave también en la validación e } \\
\text { interpretación de las noticias. }\end{array}$ \\
\hline $\begin{array}{l}\text { Búsqueda de } \\
\text { valor añadido a la } \\
\text { comunicación }\end{array}$ & $\begin{array}{l}\text { La llamada telefónica es la principal vía para estrechar lazos con el país de } \\
\text { origen y la familia. La voz aporta una dimensión más cercana. }\end{array}$ \\
\hline $\begin{array}{l}\text { Ruptura con la } \\
\text { invisibilidad mediática }\end{array}$ & $\begin{array}{l}\text { Internet es una fuente de información alternativa frente a la invisibilidad } \\
\text { mediática de las sociedades de origen. }\end{array}$ \\
\hline $\begin{array}{l}\text { Multiplicar vínculos } \\
\text { con compatriotas }\end{array}$ & $\begin{array}{l}\text { Facebook permite aumentar la red de relaciones con compatriotas, tanto en } \\
\text { la sociedad de partida como en la de destino. }\end{array}$ \\
\hline $\begin{array}{l}\text { Consolidación } \\
\text { de relaciones de } \\
\text { amistad y trabajo con } \\
\text { autóctonos }\end{array}$ & $\begin{array}{l}\text { Whatsapp se está revelando como una forma de profundizar y consolidar } \\
\text { relaciones de amistad y trabajo con autóctonos. }\end{array}$ \\
\hline
\end{tabular}

Fuente: elaboración propia. 


\subsection{Los medios latinos}

Tal y como explican los representantes de las federaciones latinas Fedelatina y Fasamcat, así como los de Radio Barcelona Latina, entre otros entrevistados, en sus años de bonanza, desde 2003 a 2009, los medios latinos crearon el concepto de público latino, reuniendo a una parte significativa de la comunidad dispersa en los medios generalistas. Cohesionaron a la diáspora en torno a una agenda temática, estableciendo espacios públicos de debate y asentando las bases de una comunidad de comunicación (Habermas, 1999, p. 560) latina. La información de servicios (Walker, 1999; Dallemagne et al., 2012) fue fundamental para que las personas inmigrantes pudieran regularizar su situación, construyendo puentes con la sociedad de acogida, según se desprende, también, de las entrevistas en profundidad realizadas a representantes de medios y federaciones latinas.

Sin embargo, la crisis afectó sobremanera a la prensa latina que años antes había conseguido tiradas de más de 100.000 ejemplares, con los desaparecidos Latino y Sí, se puede a la cabeza. Una financiación inestable, la dependencia de las subvenciones y anuncios institucionales, los bajos salarios de los periodistas y la falta de profesionalidad de los contenidos explican su decadencia. Según Lester Burton, director de El Periódico Latino, otra de las causas se debe a que estaban dirigidos por españoles que no entendían bien el concepto latino. Reproducían una imagen estigmatizada de este colectivo como personas sin formación.

De las entrevistas realizadas se desprende que la paulatina desaparición de los medios latinos deja huérfano al tejido asociativo. Queda tocada, así, la relación simbiótica entre ambos actores, porque el medio de comunicación se nutría de las actividades asociativas y las asociaciones encontraban un canal de difusión natural de sus actividades, a menudo ignoradas por los medios autóctonos. Las actividades asociativas ahora pasan inadvertidas, lo que perjudica la participación y adhesión de asociados.

De la investigación se concluye que algunas personas desconocen los medios latinos; otras, los han consultado, pero no recuerdan el nombre; e incluso algunas personas los confunden con la prensa gratuita. Esto nos lleva a deducir que, probablemente, la mayoría de los medios latinos no tienen una imagen de marca muy trabajada, a excepción de los desaparecidos Sí, se puede y Latino (GómezEscalonilla, 2008, pp. 61-102). Al parecer, en Barcelona se pasa de un 
modelo de consumo marcado por la prensa escrita gratuita (Altarriba et al., 2008) a otro de carácter provisional, radial. Esta transición será más o menos larga en función de la solidez de los proyectos digitales que se impulsen en la comunidad hispanoamericana. En este sentido, en los relatos de las experiencias mediáticas, la radio tiene un especial protagonismo, como afirman las mujeres dominicanas A6 y H1, la colombiana D3, el gerente de Radio Barcelona Latina, Jorge Sánchez, y la ex locutora de La Bomba Latina, Omaira Beltrán. En la mayoría de ocasiones, se cita por el nombre de la emisora, lo que indica una imagen de marca más identificada y bien definida por los latinos en la asunción de sus contenidos. De ahí que buena parte del consumo de medios latinos se centre en la radio.

El consumo de las noticias de un medio latino refuerza los vínculos con su nación de partida y el sentido de pertenencia. Y esta actualización de los vínculos con el colectivo al que pertenecen es fundamental para continuar dotando de sentido y contenido a la propia identidad individual. En la recepción mediática, la nacionalidad de cada país prevalece sobre el sentimiento de pertenencia a la comunidad latina como expresión de la macroidentidad. Estar al corriente de la actualidad del país de origen permite participar y opinar en programas de radio, ganar complicidad en las conversaciones con otros compatriotas sobre sucesos importantes o emocionarse al escuchar noticias de la ciudad natal. Son aspectos que trascienden el consumo y la apropiación convencionales de un público que no ha emigrado:

«Y realmente cuando yo escuchaba la emisora me llenaba de energía. Me emocionaba escuchar; y cuando decían algo bonito de mi ciudad, de Cali, pues me emocionaba muchísimo más (...) Todo el tiempo estoy escuchando las emisoras latinas, porque me gusta saber lo que está pasando al otro lado del mundo, tratar como de apoyar a la gente, darme cuenta, opinar y cuando me encuentro a un colombiano decirle ¿te has dado cuenta ha pasado esto y esto y esto? Qué bien, qué opinas, y hacer como una pequeña tertulia ahí. Porque, por lo menos, si yo no sé algo y vamos hacia el trabajo y tenemos 15 minutos tú me empapas de información y viceversa ...» (Mujer D3).

Cuando se habla de este tipo de consumo a menudo se emplean expresiones como «conectar con lo latino» (Mujer A6), donde 
cobran especial importancia verbos cuyas estructuras gramaticales requieren de otras personas de la misma comunidad o de ese mundo colectivo que se comparte. El punto de partida siempre es el mismo, una noticia que alude a una ciudad o a un país; lugares que simbolizan lo colectivo. Esos espacios marcan la transición al recuerdo personal, biográfico y hacen aflorar emociones.

La música es, probablemente, la expresión colectiva de mayor proyección de las naciones latinas. Precisamente por esto, la música también está en el corazón de este consumo. A modo de ejemplo, en las entrevistas en profundidad, la periodista colombiana Omaira Beltrán comentaba: «Me gusta la música de la Bomba». Esta área de la recepción remite a las tradiciones culturales en las que se ha crecido y en las que la música ocupa un papel fundamental en Hispanoamérica. La música está, a su vez, íntimamente entretejida con el mundo subjetivo, por lo que a través del mundo cultural emergen las emociones.

Por otra parte, la dimensión cultural (Habermas, 1999) que se había activado con el consumo individual de la música también genera una onda expansiva que cruza las fronteras del sujeto. Cuando un dominicano escucha merengue se pone en contacto con su tradición cultural. Y en este diálogo puede desarrollar mecanismos de actualización de su tradición (Habermas, 2008). La suma de estos procesos individuales, que contribuyen a que la tradición evolucione, son lentos y difícilmente perceptibles a simple vista. La música latina está evolucionando rápidamente gracias a la diáspora que la consume bajo experiencias y sociedades de acogida diferentes.

La música latina tiene uno de sus momentos álgidos en las fiestas veraniegas, gracias a un modelo cultural auspiciado en Barcelona por Fedelatina, una de las federaciones latinas más importantes. En ellas se entrelazan aspectos sociales y culturales, porque si bien estas fiestas se celebran los días nacionales de cada país, sus espectáculos centrales son grandes conciertos musicales. Desde la recepción individual, el consumo de estas noticias se filtra a través de pautas de interpretación sociales y culturales. De un lado, se produce una identificación con estas celebraciones colectivas que remiten a códigos nacionales; y por el otro, con uno de los elementos importantes de las culturas latinas, la música. 


\section{TABLA 4}

\section{TIPOLOGÍA MOTIVACIONAL DE LAS ELECCIONES MEDIÁTICAS (MEDIOS LATINOS):}

\begin{tabular}{|l|l|}
\hline 1. El modelo de consumo radial & $\begin{array}{l}\text { Tras la crisis de la prensa latina, los medios que más capacidad de } \\
\text { resistencia están demostrando son las radios. Han desarrollado una } \\
\text { larga trayectoria en el trabajo comunitario y representan un modelo } \\
\text { de recepción mediática muy participativo. }\end{array}$ \\
\hline $\begin{array}{l}\text { 2. Identificación nacional } \\
\begin{array}{l}\text { 3. Voluntad de participar en la } \\
\text { vida comunitaria }\end{array}\end{array}$ & $\begin{array}{l}\text { Los parámetros nacionales de los latinos fortalecen los } \\
\text { sentimientos de pertenencia colectivos. }\end{array}$ \\
\hline $\begin{array}{l}\text { 4. La música latina, una latinos son un vehículo para que el público comparta } \\
\text { motivación transversal }\end{array}$ & $\begin{array}{l}\text { La música es un contenido central de estos medios y una } \\
\text { motivación que trasciende los vínculos nacionales. }\end{array}$ \\
\hline
\end{tabular}

Fuente: elaboración propia.

\subsection{La importancia de otros actores sociales}

La comunidad latina ha desarrollado una poderosa estructura asociativa que no se reduce a las numerosas asociaciones de diferentes nacionalidades y regiones, aunque sean muy desiguales en el número de afiliados y poder de convocatoria. Además, existen asociaciones de carácter cultural y profesional y federaciones de asociaciones de cada una de las nacionalidades más representativas en Cataluña.

Sólo en Barcelona, hay federaciones de asociaciones de cada una de las nacionalidades más representativas. Ernesto Carrión, secretario de Fepercat (Federación Peruana de Cataluña), dibuja el panorama asociativo al detalle:

«El tejido asociativo, en este momento de la crisis quizás ya no tanto, pero llegó un momento muy, muy organizado. Sólo de América Latina hemos llegado a tener 13 federaciones, ya no hablo de asociaciones, sino de federaciones en las cuales en cada federación había un promedio de 15 a 20 asociaciones. Hemos llegado a tener 3 federaciones de Ecuador, 3 de Perú, 2 de Bolivia» (...)

En la actualidad, también, hay tres federaciones latinas que pugnan por ser la más representativa de la comunidad y la 
interlocutora oficial con la sociedad anfitriona: Fedelatina, Fasamcat y Espai Latino.

Fedelatina, en su primera década de existencia, ha acumulado una gran experiencia en la coordinación y el trabajo en red con las asociaciones, en el empuje del tejido asociativo y en la comunicación con las administraciones. Según explica la locutora mexicana Teresa Salas, la participación del presidente de Fedelatina, Javier Bonomi, durante algunos años en el programa Actualidad Latina, de Radio Barcelona Latina, fue clave para conseguir presionar a las administraciones con el objeto de que los menores y adolescentes que habían sido reagrupados también vinieran con permiso de trabajo.

Fedelatina lleva muchos años colaborando de forma sinérgica con medios latinos. Sin embargo, la irrupción de la crisis y el cierre de muchos de ellos han hecho que las actividades de la federación pierdan difusión en la comunidad. Y si no hay información, deja de existir para la comunidad latina.

En opinión de la presidenta de Fasamcat, Laura Rojas, esta entidad tuvo un papel central al ofrecer los primeros contactos a los medios latinos y conseguir que participaran en eventos de la sociedad barcelonesa. Rojas critica la imagen que, en general, los medios latinos proyectan de la diáspora, aunque reconoce que son los que más cobertura han prestado a sus actividades. Generalmente, los medios autóctonos sólo acuden a Fasamcat cuando se producen crímenes o tragedias en algún país hispanoamericano "y entonces empiezan a buscar el referente» para entrevistarlo y ampliar información.

Esta tricefalia en las federaciones no es únicamente el resultado de un crecimiento desenfrenado en el campo del asociacionismo latino, como argumenta el secretario de Fepercat (Federación Peruana de Cataluña), sino también de la politización de una sociedad anfitriona compleja, como apunta la presidenta de Fasamcat, Laura Rojas. Las tres han tenido un papel clave en el nacimiento y en la evolución de los medios latinos y han servido de enlace con los generalistas si estos necesitaban ampliar información sobre los países hispanoamericanos cuando se producían noticias trágicas.

A medida que las comunidades minoritarias crecen, también se convierten en un segmento de población con necesidades específicas que justifican el surgimiento de otros actores sociales. El tejido asociativo representa colectivamente a la comunidad latina; los 
movimientos cristianos satisfacen las necesidades espirituales en una comunidad con profundas creencias religiosas y los despachos de abogados hacen frente a la indefensión legal. Pero pronto estos actores sociales asumen nuevas funciones y capacidades en el seno de la comunidad latina. Hoy sus cometidos son tan relevantes que están en la vertebración de las colonias hispanoamericanas $\mathrm{y}$, ante el retroceso de los medios latinos, ganan relevancia en sus comunidades de comunicación. Porque no sólo cohesionan los diferentes estratos sociales de la sociedad minoritaria, las federaciones y asociaciones latinas, por ejemplo, también participan en la arquitectura del relato de los medios latinos, contrarrestan el discurso de los medios generalistas y son interlocutores privilegiados de las administraciones públicas.

Los movimientos cristianos y político-religiosos que consolidan en España los latinos nacen con la voluntad de llevar la experiencia religiosa a su nuevo destino. En consecuencia, tienen una orientación claramente transnacional y una estrategia diaspórica en su implantación. Son de creación más reciente que las asociaciones y logran implicar a personas que no habían sentido la llamada del asociacionismo inmigrante más convencional. Son espacios de encuentro con otros latinos que activan dinámicas sociales con los más necesitados. Por tanto, su ámbito de acción no puede ser entendido tanto desde la óptica nacional de las asociaciones de latinos que luchan por reivindicar la identidad colectiva y defender la imagen de la comunidad en Barcelona, sino en la coordinación de mecanismos de solidaridad con aquellos que han llevado peor la experiencia migratoria y han sufrido las consecuencias más severas del sistema de la sociedad de acogida.

Amigos Mira representa un nuevo modelo de asociación con tintes políticos y base cristiana. Tiene una orientación claramente transnacional, porque entiende su actuación más allá de las barreras del estado nación colombiano y se extiende donde llega la diáspora latina. En España no se presenta como un movimiento político, sino como una asociación, tal y como está registrada. Sus máximos responsables colaboran activamente con los medios latinos que quedan en España y, en especial, con las radios latinas, para hablar de sus actividades y participar en foros sobre inmigración.

La Iglesia Pentecostal Unida de España es un movimiento evangelista que se inicia a principios del siglo XX en Estados Unidos y, desde este país, se expande por México y el resto de 
Hispanoamérica. Es un enclave idóneo para conocer a otros latinos y ocupar el tiempo libre con variadas actividades:

«Aquí hay mucha gente que los domingos no tienen para dónde ir, porque hay gente que está sola, no tiene familia, y ¿qué hacemos?, hacemos actividades dentro de la iglesia, para que ellos estén aquí. Es mejor que estén en un lugar donde puedas progresar, aprender, se dan clases, se dictan cursos, entonces ellos aprenden» (Pastor Edison Mendoza).

Los despachos de abogados especializados en extranjería desarrollan un trabajo que rebasa los límites tradicionales de esta actividad profesional. Encontramos abogados hispanoamericanos que tras haber pasado por la misma experiencia migratoria establecen una relación más estrecha con sus clientes. Sus servicios no se acaban en el ámbito privado, sino que emplean su web y las redes sociales para tomar partido en la defensa de los derechos de las minorías, un concepto transversal a todas las nacionalidades de la diáspora. Participan en debates y son consultados como expertos en la materia:

«Estamos muy acostumbrados a que los medios de comunicación nos criminalicen. La criminalización es brutal, muchas veces lo intentamos decir nosotros, si un español ha violado a 6 niños el titular es «Imputan a un agresor de niños en Malgrat de Mar»; si es un ecuatoriano el titular es «Imputan a un ecuatoriano en Malgrat de Mar de haber pillado 6 niños». Si ese ecuatoriano no tiene papeles «Imputan a un inmigrante ilegal en Malgrat de Mar», pero de qué va esto...» (Vicente Marín).

El abogado Vicente Marín ha creado uno de los portales de referencia sobre inmigración en España con información de calidad y permanentemente actualizada. Parainmigrantes.com, se ha convertido en una fuente de información fiable no sólo para los medios étnicos, sino también para los generalistas, los gabinetes de comunicación de los registradores y las administraciones. A diferencia de otros despachos de abogados barceloneses dirigidos por personas de origen hispanoamericano como Legalcity, Legalteam e Iurismundi, el granadino Vicente Marín imprime un estilo aséptico a sus contenidos en línea, algo que le ha costado algunas críticas. 
En definitiva, lo que hemos denominado como otros actores (asociaciones y federaciones, iglesias o despachos de abogados), han contribuido a generar espacios de comunicación, información y también de socialización en una comunidad en la que los medios latinos han ido perdiendo el protagonismo que tuvieron hace pocos años. Estos nuevos actores, no sólo cohesionan los diferentes estratos de la comunidad hispanoamericana, constituyéndose en espacios fundamentales de libertad de expresión en temas de inmigración; también participan en la construcción de los relatos de los medios latinos; contrarrestan el discurso estereotipado y muy sesgado de los medios generalistas y consolidan su papel como fuente de información y líderes de opinión; constituyéndose, además, como interlocutores directos con las administraciones públicas.

\section{CONCLUSIONES}

El presente artículo ha tenido por objeto analizar la experiencia mediática de la comunidad hispanoamericana partiendo de cuatro dimensiones clave que conforman distintas tipologías motivacionales y maneras de acercarse al consumo mediático. Los medios generalistas, el consumo mediático dirigido a la sociedad de origen, el papel híbrido que juegan los medios latinos entre la sociedad de origen y la de acogida y, finalmente, lo que hemos denominado otros actores, configuran un mapa global de las distintas tipologías y causas de la apropiación mediática por parte de la comunidad hispanoamericana. Dicha forma de consumo mediático tiene unos componentes motivacionales y afectivos distintos al público de las sociedades de acogida. Posee sus propios códigos y patrones socioculturales, distintos a los de la sociedad receptora. No obstante, tal y como se detalla en el marco teórico, es necesario abandonar la idea preconcebida de que la inmigración es un fenómeno aislado de la sociedad de acogida.

Los vínculos familiares ejercen una gran influencia en una de las dos grandes áreas en las que se divide la recepción mediática de la diáspora hispanoamericana, la que mira hacia la sociedad de origen. Son precisamente los lazos familiares los que explican la prevalencia de las necesidades comunicativas por encima de las generadas por la información. Como saber global y cotidiano, trasfondo de 
convicciones, el mundo de la vida se distribuye en los círculos sociales que gravitan alrededor del individuo. Este patrimonio de ideas compartidas, resorte de los procesos de integración social, socialización y reproducción cultural, se interioriza con mayor intensidad en la medida en la que los círculos sociales son más nucleares. En este sentido, la familia mantiene más fuertes los vínculos de solidaridad grupal y más arraigados e incuestionados los criterios de valoración que emanan del grupo. A través de la familia, las interacciones y saberes compartidos actúan en la recepción mediática y en los procesos sociales y culturales que se derivan del consumo inicial. Es el grupo social de referencia con el que se mantienen patrones de interpretación más afines y compartidos. La cultura colectivista hispanoamericana, la importancia troncal para la vida en comunidad y su papel de brújula en la experiencia migratoria, colocan a la familia en el frontispicio de las apropiaciones de las TIC.

En cambio, en la segunda gran área en la que transcurre el consumo mediático, la sociedad de acogida, el influjo de la nacionalidad del hispanoamericano es la que marca la pauta. Los parámetros nacionales son los que explican la búsqueda de información del país de origen y la identificación con sus contenidos. No sólo influye en lo que se consume, sino en cómo se consume, los mecanismos de defensa del individuo frente a las imágenes mediáticas estereotipadas dominantes y los procesos de socialización, sociales y culturales, que se derivan del escenario inicial del impacto mediático. En este sentido, la lealtad al país de origen en las apropiaciones mediáticas está en el trasfondo del consumo, pese a la globalización y la movilidad de las migraciones internacionales. La dieta mediática se mueve, prioritariamente, en parámetros nacionales; pero, en segundo lugar, también supranacionales, ya que se alude a sentimientos de pertenencia más generales como la identidad latina.

Así, partiendo de una perspectiva alejada de los prejuicios e intereses de la sociedad de acogida, se ha querido comprender las razones e implicaciones de la recepción mediática en los procesos migratorios de la comunidad hispanoamericana. Desde una posición que tiene más en cuenta la voz de las personas inmigradas, se ha mostrado cómo los hábitos mediáticos se reconstruyen a partir de las propias interacciones, creando una experiencia y una identidad que dota de nuevo sentido al proceso migratorio. Se abre una forma distinta de aproximarse a la recepción mediática de la diáspora que pone el énfasis, no sólo en el papel que juegan los medios generalistas, 
sino en aspectos que rodean al consumo mediático como la familia y la identidad nacional. Una manera de acercarnos a la recepción mediática que también incorpora el análisis de las interacciones con los llamados medios latinos y con lo que hemos denominado como otros actores sociales, que activan mecanismos de solidaridad y establecen canales sólidos para la participación cívica y política de la comunidad diaspórica.

\section{BIBLIOGRAFÍA}

Altarriba, M., Aira, J. A., Canosa, F., Concepción, L. G., Masip, P., Medina, A., y Sort, J. (2008). Usos i actituds dels immigrants davant dels mitjans de comunicació. Barcelona: Consell de l'Audiovisual de Catalunya. Recuperado de https://www.mesadiversitat.cat/sites/default/files/2017-11/ usos_actituds_immigrants_mitjans_ramon_llull.pdf

Bailey,O.G.(2012).DiasporasinOnlineSpaces:PracticesofSelf-Representation and Belonging. En I. Rigoni y E. Saitta (Eds) Mediating Cultural Diversity in a Globalised Public Space (pp. 21-33). London: Macmillan. Recuperado de https://link.springer.com/chapter/10.1057/9781137283405_2

Bañón, A. (Coord.) (2008). Introducción. Discurso e inmigración en España. Una aproximación crítica. Discurso \& Sociedad, 2 (4), 686-688.

Bauböck, R. (2004). Cómo transforma la inmigración a la ciudadanía: perspectivas internacionales, multinacionales y transnacionales. En R. Zapata y A. Aubarell, Inmigración y procesos de cambio. Europa y el Mediterráneo en el contexto global (pp. 177-214). Barcelona: Icaria.

Bernárdez, A. (Dir.) (2007). Mujeres inmigrantes en España. Representaciones en la información y percepción social. Madrid: Fragua.

Concepción, L. y Medina, A. (2015). Hacia un modelo de análisis del discurso más comunicacional. África en los digitales españoles. Estudios sobre el Mensaje Periodístico, 21(2), 773-791. doi: http://dx.doi.org/10.5209/rev_ ESMP.2015.v21.n2.50883

Concepción, L. y Medina, A. (2011). Claves teóricas para una nueva visión de la recepción mediática desde la experiencia migratoria. Correspondencias y Análisis, 1, 369-384. doi: https://doi.org/10.24265/cian.2011.n1.21

Concepción, L., Rodrigo, M., y Medina, P. (2008). Niveles semánticos de las representaciones sociales de la inmigración subsahariana. Los sucesos de Ceuta y Melilla según ABC. Estudios sobre el Mensaje Periodístico, 14, 129-148.

Checa, J., y Arjona, A. (2011). Españoles ante la inmigración: el papel de los medios de comunicación. Comunicar, 37, v. XIX, 141-149. doi: http:// dx.doi.org/10.3916/C37-2011-03-06 
Dallemagne, G., Echevarría, L., y Fernández, A. (2012). Migraciones transnacionales y políticas de representación en España: los discursos sobre colectivos latinoamericanos en dos medios dirigidos a minorías migrantes. Revista de Ciencias Sociales, 29, 132-159.

Georgiou, M. (2014). Mediane: media in Europe for diversity inclusiveness. Methodological Paper. London: Council of Europe.

Giró, X. (2006). Solidaritat delimitada. Estudi de la cobertura televisiva dels fets al voltant de la tanca de Melilla de l'octubre de 2005. Quaderns del CAC, 23/24, 37-48.

Giró, X., y Jarque, J. M. (2006). Prensa escrita e inmigración: Estudio sobre la opinión de los diarios sobre la inmigración procedente de fuera de la Unión Europea y sobre la cobertura informativa de conflictos destacados que tienen relación con ella (octubre 1999-junio 2002). Zer, 20, 251-270.

Gómez-Escalonilla, G. (Coord.) (2008). Voces de la inmigración. Medios latinos en Madrid. Madrid: Universitas.

Gómez-Escalonilla, G., y Santín, M. (2012). Los medios inmigrantes como referentes de certidumbre social: análisis de la prensa latina en las capitales de EE.UU. y España. Prisma Social, 8. Recuperado de http://www.isdfundacion.org/publicaciones/revista/numeros/8/secciones/ tematica/03-medios-inmigrantes-referentes-certidumbre.html

Gualda, E., y Montes, A. (2007). Prensa local e inmigración en Huelva: textos, imágenes y efectos sociales. En J. J Igartua y C. Muñiz (Eds.). Medios de comunicación. Inmigración y sociedad (pp.127-148). Salamanca: Ediciones Universidad de Salamanca.

Habermas, J. (2008). El discurso filosófico de la modernidad. Madrid: Katz Editores.

Habermas, J. (1999). Teoría de la acción comunicativa, I. Racionalidad de la acción y racionalización social. Teoría de la acción comunicativa, II. Crítica a la razón funcionalista. Madrid: Santillana.

Hall, S. (1980). Codificar/decodificar. En Culture, Media, Language. Working Papers in Cultural Studies, 1972-79. Londres: Routledge \& The CCCS University of Birmingham.

Hernández, C., y Alcoceba, J. A. (2015). Socialización virtual, multiculturalidad y riesgos de los adolescentes latinoamericanos en España. Icono 14, 13, (2), 116-141. Recuperado de http://www.icono14.net/ojs/index.php/ icono14/article/view/787

Hurley, R. J., Jensen, J., y Weaver, A. et al. (2015). Viewer Ethnicity Matters: Black Crime in TV News and Its Impact on Decisions Regarding Public Policy. Journal of Social Issues, 71, 155-170. doi: https://doi.org/10.1111/ josi.12102

Igartua, J. J., y Frutos, F. J. (2016). Procesos de recepción y efectos sociocognitivos de películas sobre inmigración. El papel moderador del prejuicio hacia inmigrantes. Migraciones, 40, 33-61. doi: https://doi. org/10.14422/mig.i40.y2016.009 
Igartua, J. J., y Muñiz, C. (Coord.). (2007). Medios de comunicación, inmigración y sociedad. Universidad de Salamanca. Recuperado de https://dialnet.unirioja.es/servlet/libro?codigo $=11842$

Igartua, J. J., Otero, J., y Muñiz, C. et al. (2006). Efectos cognitivos y afectivos de los encuadres noticiosos de la inmigración. Ponencia presentada en las V Jornadas de Comunicación: Medios de comunicación, inmigración y sociedad. Retos y propuestas para el siglo XXI. Universidad de Salamanca. Recuperado de https://es.scribd.com/document/40306488/ Efectos-cognitivos-y-afectivos-de-los-encuadres-noticiosos-de-lainmigracion

Martínez, Y., y Huertas, A. (2014). Las adolescentes migrantes ante las Tecnologías de la Información y la Comunicación (TICs): prácticas y relaciones socio-afectivas. En A. Huertas y M. Figueras (Eds.) Audiencias Juveniles: recepción, usos y hábitos mediáticos (pp. 175-190). Bellaterra: Institut de la Comunicació-Universitat Autònoma de Barcelona.

Mastro, D. (2015). Why the Media's Role in Issues of Race and Ethnicity Should be in the Spotlight. Journal of Social Issues, 71, 1-16. doi: https:// doi.org/10.1111/josi.12093

Moon, S. J. (2003). Media Consumption Patterns of Korean Immigrants in the U.S.: A Study of Korean Immigrants' Media Uses and Gratifications in Chicago's Koreatown. Paper submitted to the Hawaii International Conference on Social Science Honolulu, Hawaii, June 12-15.

Morley, D. (1997). La recepción de los trabajos sobre la recepción. Retorno al público de Nationwide. En D. Dayan (Comp.). En busca del público. Recepción, televisión, medios. (29-48). Barcelona: Gedisa.-

Morley, D. (1996). Televisión, Audiencias y Estudios Culturales. Buenos Aires: Amorrortu editores.

Navarro, L. (2015). Televisión pública y diversidad cultural en España: el caso de los programas dirigidos a «inmigrantes». Migraciones, 38, 111-135. doi: https://doi.org/10.14422/mig.i38y2015.005

Ortiz, M., y Behm-Morawitz, E. (2015). Latinos' Perceptions of Intergroup Relations in the United States: The Cultivation of Group-Based Attitudes and Beliefs from English- and Spanish-Language Television. Journal of Social Issues, 71, 90-105. doi: http://onlinelibrary.wiley.com/doi/10.1111/ josi.12098/full

Red Acoge. (2015). Estudio sobre periodismo e inmigración. Corta con las etiquetas: medios de comunicación libres de xenofobia. Inmigracionalismo 2. Recuperado de https://www.redacoge.org/mm/file/2015/Intervenci\%C3\% B3n\%20Social/Inmigracionalismo2.pdf

Retis, J. (2013). La condición transnacional de las prácticas comunicativas y los retos de la ciudadanía cultural: Latinoamericanos en contextos diaspóricos. Ponencia presentada en el congreso Academia Confronts Emergent Communication Practices and Technopolitics, City University, London. 
Retis, J., y Benavides. J. L. (2005). Miradas hacia Latinoamérica: la representación discursiva de los inmigrantes latinoamericanos en la prensa española y estadounidense. Revista Palabra Clave, 13, 93-114. Recuperado de http://palabraclave.unisabana.edu.co/index.php/palabraclave/article/ view/1462/1630

Rigoni, I., y Larrazet, Ch. (2014). Media and Diversity: A Century-Long Perspective on an Enlarged and Internationalized Field of Research. InMedia. Recuperado de http://inmedia.revues.org/747

Sabés-Turmo, F. (2009a). Los medios de comunicación para la "nación latina” que vive en España. Palabra Clave, 12 (1), 107-119. Recuperado de http://palabraclave.unisabana.edu.co/index.php/palabraclave/article/ view/1454/1620

Sabés-Turmo, F. (2009b). La prensa latina en España: una experiencia comunicacional nueva. Estudio del caso de la revista Raíz. Revista F@ro, 9. Recuperado de http://web.upla.cl/revistafaro/n09/art02.htm

Sampedro, V. F. (2003). Identidad y medios nacionales en la diáspora. En V.F Sampedro (Ed.) La pantalla de las identidades. Medios de comunicación, politicas y mercados de identidad. Barcelona: Icaria.

Sendín, J. C. (2014). Joven diáspora marroquí y usos mediáticos. Estudio del proceso de adaptación post-migratoria en España. Ámbitos, 26. Recuperado de http://ambitoscomunicacion.com/2014/joven-diasporamarroqui-y-usos-mediaticosestudio-del-proceso-de-adaptacion-postmigratoria-en-espana

Soriano, J. (2009). Análisis comparado de audiencias y consumos culturales de los extranjeros en Cataluña. Barcelona: Fundación Jaume Bofill.

Strategy\&. (2015). Telco Trends for 2015+: Resumen Ejecutivo. Recuperado de http://www.strategyand.pwc.com/global/home/what-we-think/reportswhite-papers/article-display/telco-trends-2015-eps

Tortajada, I. (2009). ¿Qué hay de nuestro aquí? Cómo se perciben en los medios algunas minorías residentes en Cataluña. Zer, 14 (26), 59-80. Recuperado de http://www.ehu.eus/zer/hemeroteca/pdfs/zer26-03tortajada.pdf

Tortajada, I., Comas D’Argemir, D., y Martínez Corcuera, R. (2014). Inmigración, crisis económica y discursos radiofónicos: hacia un lenguaje excluyente. Estudios sobre el Mensaje Periodístico. 20, (2) (juliodiciembre), 899-916.

Tsagarousianou, R. (2017). Public narratives and the construction of memory among European Muslims. En C. Raudvere (Ed.) Contested Memories and the Demands of the Past: History Cultures in the Modern Muslim World (pp. 127-148). London: Palgrave Macmillan.

Walker, D. (1999). The media's role in immigrant adaptation: how first-year Haitians in Miami use the media. Journalism \& Mass Communication Monographs, 1, 158-196. 